\title{
Investigation on the Intercultural Sensitivity of English Teachers in Chinese Elementary Schools
}

\author{
Xinglei Jia* \\ School of Foreign Languages, Qingdao University, Qingdao 266000, China \\ *Corresponding author: Xinglei Jia, 1101716428@qq.com
}

\begin{abstract}
The development of technology has driven human beings into a globalized world, which requires intercultural communication competence (ICC). As its affective aspect, the subject of intercultural sensitivity (IS) is being heatedly discussed nowadays. This study focuses on the importance of intercultural sensitivity (IS) among Chinese EFL teachers and attempts to explore their current level and the possible reasons for it. For this purpose, questionnaires were distributed to 29 Chinese elementary school English teachers, and the results from the questionnaire showed that the IS level of these teachers is satisfactory, scoring high in five dimensions: interaction engagement, respect for cultural differences, interaction confidence, interaction attentiveness, and interaction enjoyment. The follow-up interview suggested that the high IS level may be a result from intercultural communication training. Moreover, this research found that Chinese teachers were more engaged and enjoyed less in view of scarce opportunities for communication in authentic cross-cultural contexts. Several suggestions and implications for further research have also been included in this article.
\end{abstract}

Keywords: Intercultural sensitivity; Intercultural communication competence; EFL teaching; Chinese elementary school

Publication date: December 2021; Online publication: December 23, 2021

\section{Introduction}

In the context of globalization, communication between countries and even individuals is becoming more extensive, and communication competence is now insufficient in intercultural contexts. This is the reason why the concept of intercultural communication competence (ICC) has been proposed. According to Portalla and Chen ${ }^{[1]}$, intercultural communication competence (ICC) is "an individual's ability to achieve their communication goal while effectively and appropriately utilizing communication behaviors to negotiate between the different identities present within a culturally diverse environment. Representing the affective aspects of ICC, intercultural sensitivity (IS) is understood as learners' positive attitudes to facilitate their understanding, appreciating, or even accepting the cultural differences ${ }^{[2]}$. Scholars believe IS is an indicator to test one's ICC level. Despite that, many countries have stressed the importance of ICC by applying it into their foreign language education policy ${ }^{[3]}$, including China; the Compulsory Education English Curriculum Standard of 2011 demonstrates the cultivation of ICC in a clear description: cultivating learners' comprehensible language application ability based on the overall development of language skills, language knowledge, emotional attitudes, learning strategies, and cultural awareness ${ }^{[4]}$. All these efforts aim to encourage foreign language teachers to employ ICC into their classroom practice. Given the great value of ICC and IS in the teaching context, much attention has been on teachers' IS level, but compared with the abundant research analyzing English teachers in foreign countries, there is minimal empirical research investigating Chinese teachers' IS ${ }^{[5]}$, especially English teachers in Chinese elementary schools. Therefore, this study attempts to explore Chinese elementary school English teachers' IS and hopes to shed some light on the development of Chinese learners' ICC. 


\section{Literature review}

\subsection{Intercultural communication competence and intercultural sensitivity}

In order to assist learners to effectively communicate with people from different cultures, many scholars have valued ICC from different aspects, such as Byram ${ }^{[6]}$, where he analyzed ICC from the aspects of knowledge, attitudes, and skills, in addition to linguistic, sociolinguistic, and discourse competence. Attitude refers to the curiosity and openness toward different cultures; knowledge refers to an individual's knowledge pertaining to social groups, products, practices, and the general processes of social and individual interaction in their own country or others; skill refers to the ability of interpreting a document from other cultures or even explaining and relating it to that of their own ${ }^{[6]}$. In contrast to Byram, Chen and Starosta defined ICC from the following three dimensions: intercultural awareness (the cognitive aspect), intercultural sensitivity (the affective aspect), and intercultural effectiveness (the behavioral aspect) ${ }^{[7,8]}$. The view that IS is the prerequisite of ICC has been widely accepted by scholars ${ }^{[3]}$. As for the connection between IS and ICC, Xiao believes that IS can directly affect the development of intercultural communication competence ${ }^{[9]}$. Judging from the above, it is not difficult to appreciate the close relationship between ICC and IS, which means that they have mutual effect on each other and cannot be discussed separately.

\subsection{Teachers' intercultural sensitivity}

The IS level of teachers, who are the main players of the English teaching classroom, has an influence on ICC teaching and students' ICC learning. Well-equipped teachers with intercultural competence are a guarantee for the implementation of the ICC teaching approach as well as the realization of ICC goals ${ }^{[10]}$. Consequently, many scholars have engaged in exploring the IS level of teachers, such as Altan; his study examined the IS of 70 Turkish preservice teachers who majored in English language teaching and found that the IS level of these teachers was high ${ }^{[11]}$. Consistent with the former research, Alaei and Nosrati also revealed that the IS level of Iranian teachers for English as a foreign language was high through their study which included 167 individuals ${ }^{[3]}$. However, Chinese scholars have not reached agreement with this result. Shao and Chen carried out a research in four senior high schools, and the data collected from 35 English teachers showed that the IS level of these Chinese senior high school teachers is high above the standard

${ }^{[12]}$. In order to expand on this, Xiao examined the intercultural sensitivity of 40 English teachers in English major in normal universities. The results revealed that the teachers' IS level remained at the moderate level but those with foreign experience shared higher IS level ${ }^{[9]}$.

Based on the above review, it can be summarized that the studies on Chinese teachers' IS in elementary schools are scarce and the argumentation is only within one group. No research compared the IS of teachers in different groups. Therefore, this study analyzes elementary school English teachers' IS in an attempt to determine their current state and possible factors which may influence the IS level. The research questions would be discussed in the later sections.

(1) What is the current level of Chinese elementary school English teachers' IS?

(2) What are the possible factors that may influence the IS level of elementary school English teachers?

\section{Method}

In order to optimize the validity and reliability of the current study, two different instruments (questionnaires and phone interviews) were employed. 


\subsection{Participants}

A total of 38 Chinese elementary school English teachers completed a questionnaire, which included personal information and an intercultural sensitivity scale, developed by Wang and Zhou ${ }^{[13]}$. Among all the questionnaires, nine were excluded for repeated or mismatched information. Out of the 29 participants whose age ranged from 22 to 44, 2 were male and 27 were female. The demographic information of the teachers is shown in Table 1. Nearly half of the respondents $(48.28 \%)$ were between 20 to 30 years of age and between 31 to 41 years old, with $96.56 \%$ in total. With regard to the level of education, $68.96 \%$ had a bachelor's degree, $24.14 \%$ were MA holders, $3.45 \%$ held a PhD, and 3.45\% chose others. In terms of their major, $86.21 \%$ studied English, while $13.79 \%$ were non-English majors. Regarding the years of experience, more than half of the teachers had 0-5 years of experience, $31.03 \%$ had 6-11 years of experience, and only $3.45 \%$ had $12-17$ or above 24 years of experience. In addition, $37.93 \%$ of the participants were primary school and junior high school English teachers, respectively, whereas $24.14 \%$ were senior high school English teachers. It was also noted that $93.10 \%$ of the teachers had not travel abroad so far.

Table 1. Demographic information of the teachers

\begin{tabular}{cccc}
\hline Category & Subcategory & Number & Percentage (\%) \\
\hline Gender & Female & 27 & 93.10 \\
& Male & 2 & 6.90 \\
Age & $20-30$ & 14 & 48.28 \\
& $31-41$ & 14 & 48.28 \\
& Above 42 & 1 & 3.44 \\
Degree & Bachelor's degree & 20 & 68.96 \\
& Master's degree & 7 & 24.14 \\
& Doctor's degree & 1 & 3.45 \\
Major & Others & 1 & 3.45 \\
& English & 25 & 86.21 \\
Experience & Non- English & 4 & 13.79 \\
& $0-5$ & 16 & 55.17 \\
& $6-11$ & 9 & 31.03 \\
& $12-17$ & 1 & 3.45 \\
& $18-23$ & 2 & 6.90 \\
& Above 24 & 1 & 3.45 \\
Stages & Primary & 11 & 37.93 \\
& Junior high & 11 & 37.93 \\
& Senior high & 7 & 24.14 \\
Been abroad & Yes & 2 & 6.90 \\
& No & 27 & 93.10 \\
Total & - & 29 & 100 \\
\hline
\end{tabular}

\subsection{Instrument}

In order to objectively measure the intercultural sensitivity level of the participants, an intercultural sensitivity questionnaire, the ISS-15 ${ }^{[13]}$ was adapted. The ISS-15 is an abbreviation of Chen's and Starosta's 24-Item Intercultural Sensitivity Scale ${ }^{[2]}$, and it retains a high level of reliability as well as validity. To be specific, the 24-Item Intercultural Sensitivity Scale, as its name suggests, comprises of 24 items, referring to five aspects: interaction engagement, respect for cultural differences, interaction 
confidence, interaction enjoyment, and interaction attentiveness; whereas, the ISS-15 version limits the number of the items in each aspect to three.

In this study, the questionnaire was divided into two parts. The first part comprised of nine questions to obtain the participants' background information, while the second part comprised of the Intercultural Sensitivity Scale, which has 15 statements rated on a 5-point Likert scale ranging from 1 (strongly disagree) to 5 (strongly agree). It has been noted that the 5-point Likert scale can indicate the degree of agreement

${ }^{[14]}$. Based on Altan's 5-Point Likert Scale Agreement Level ${ }^{[11]}$, it can be divided into "very high" (4.515.0), "high" (3.51-4.50), "uncertain" (2.51-3.50), "low" (1.51-2.50), and "very low" (1.00-1.50).

\subsection{Data collection and statistical analysis}

The data collection took about a week. First, the information of the questionnaire was transcribed into relevant options and added to an applet called Wenjuanxing before being delivered to different individuals through WeChat. In total, 38 individuals responded, but 9 of them were not included in the study due to missing or wrong information. The descriptive statistics (mean and standard deviation) were analyzed using SPSS version 23.0, so as to determine the teachers' IS level. Then, three phone interviews were recorded and transcribed to interpret the reasons behind the IS level of the teachers.

\section{Results and discussion}

\subsection{IS level of Chinese elementary school English teachers}

The total mean score of the ISS-15 scale was 3.7701, which is under the category of "high," based on Altan's Five-Point Likert Scale Agreement Level. This means that the IS level of the participating Chinese elementary school English teachers is high. The mean scores for the five dimensions of IS are shown in Table 2. As for the ranking, "respect for cultural differences" ranked first, with the highest mean score of 3.8851, followed by "interaction engagement," with a score of 3.8391. The third is both, "interaction confidence" and "interaction attentiveness," with the same mean score of 3.7701. The last is "interaction enjoyment," with the lowest mean score of 3.5862. According to Altan, the agreement level of all the dimensions is high.

Table 2. Mean scores of each dimension in the ISS scale

\begin{tabular}{cccccccc}
\hline Dimension & Minimum & Maximum & Mean & Ranking & SD & Agreement \\
\hline Respect for cultural differences & 2.00 & 5.00 & 3.8851 & 1 & .88764 & High \\
Interaction engagement & 2.67 & 5.00 & 3.8391 & 2 & .52418 & High \\
Interaction confidence & 2.67 & 5.00 & 3.7701 & 3 & .55709 & High \\
Interaction attentiveness & 3.00 & 4.67 & 3.7701 & 3 & .40925 & High \\
Interaction enjoyment & 2.00 & 5.00 & 3.5862 & 4 & .83407 & High \\
Total & 3.00 & 4.67 & 3.7701 & & .42821 & High \\
\hline
\end{tabular}

The data revealed that the Chinese elementary school English teachers in this research have high intercultural sensitivity (3.7701). The highest mean score of "respect for cultural differences" among the five dimensions suggests that Chinese EFL teachers do respect the values of other cultures and they can accept the opinions from their culturally different counterparts. In addition, the high level of interaction engagement is an evidence indicating that the teachers were willing to participate and were open-minded. Interaction confidence and interaction attentiveness shared the same mean score (3.7701), of which the former indicated that the teachers were sure of themselves in intercultural communication, while the latter 
proved that the teachers would like to know more about cultural differences and were sensitive to the subtle meanings expressed by interlocutors. The low score of interaction enjoyment suggested that the teachers have negative attitudes toward conversations with people from different cultures. This negative attitude is consistent with two other studies, which have investigated Chinese English teachers' IS ${ }^{[9,12]}$. The aforementioned studies explained that it is a result from inadequate opportunities in communicating with foreigners or ICC training. Despite this similarity for the low rating of interaction enjoyment, the ranking of the other four dimensions in this study is also similar to Xiao's research. He stressed that most Chinese have a high degree of concentration during conversation, but they are too nervous to experience the pleasure for fear of "losing face" (face threatening theory) ${ }^{[9]}$. Other than that, the high level of "respect for cultural differences" has been proven by former studies, and all of those studies have found that it possessed the highest score ${ }^{[3,9,11,12]}$. It seems that the sense of respect for cultures is shared universally.

\subsection{Possible reasons for the IS level}

During the following interview of three teachers, the teachers expressed that by attending the recent ICC courses as well as the combination of teaching and learning experience could have been the reasons for their high IS level. After the ICC courses, they learned that the basic ICC knowledge is closely related to cultures, and it can even shape customs as well as habits. In this way, they perceived the great value of ICC and were prepared to evaluate it from the affective aspect, namely their perception of intercultural sensitivity has improved. As for teaching and learning experience, they were once learners who focused on attaining ICC knowledge, but now, they are both teachers and learners, offering them a deep insight into the values or meaning behind the phenomenon. With regard to interaction enjoyment, which ranked last, they felt that it is a result from the lack of authentic context in real life, such as scarce opportunities for intercultural conversation. They also mentioned that although surfing the internet would provide certain information about different cultures, the fragments might be falsified or one-sided. As a result, the lack of opportunity to be in touch with the real background of other countries has been attributed to their total devotion to conversations and has limited their interaction enjoyment.

\section{Conclusion}

This study investigated the IS level of Chinese elementary school English teachers through questionnaires and follow-up interviews. The results showed that the participating Chinese EFL teachers have a high level of IS. This satisfactory result might have been related to the influence of the intercultural course that the teachers took during their college life. Other than that, the results also indicated that the low score of interaction enjoyment is closely related to the unnatural situation during intercultural communication and the face-threatening act. Therefore, it is necessary to look for more ways to increase the frequencies for teachers to be involved in intercultural communication; for example, inviting teachers to conferences held by foreigners or inviting scholars from other cultures to participate in local teaching programs through online teaching tools, thus providing more opportunities for interaction with people from diverse cultures. In view of the limited number of participants, the interpretation from this study may not be generalized to other groups. In the future, studies with a larger sample size are required to ensure more precise and valid findings. In a nutshell, the IS level of Chinese EFL teachers is still a contentious issue, requiring further discussion. More studies should be conducted to discuss and compare the IS level of Chinese primary school and middle school English teachers.

\section{Disclosure statement}

The author declares that there is no conflict of interest. 


\section{References}

[1] Portalla T, Chen GM, 2010, The Development and Validation of the Intercultural Effectiveness Scale. Intercultural Communication Studies, 19(3): 21-37.

[2] Chen GM, Starosta WJ, 2000, The Development and Validation of the Intercultural Communication Sensitivity Scale. Human Communication, 3: 1-15.

[3] Alaei MM, Nosrati F, 2018, Research into EFL Teachers' Intercultural Communicative Competence and Intercultural Sensitivity. Journal of Intercultural Communication Research, 1-14.

[4] Jin H, 2015, Research on the Cultivation of Intercultural Communication Competence in English Teaching. Curriculum Materials and Teaching Methods, 35(11): 80-85.

[5] Wang XY, Pan YL, 2019, Development Status and Enlightenment of Cross-Cultural Foreign Language Teaching Research in China - Based on Bibliometric Analysis (2000-2018). Foreign Language Circles, 2019(4): 76-84.

[6] Byram M, 1997, Teaching and Assessing Intercultural Communicative Competence, Multilingual Matters, Clevedon.

[7] Chen GM, Starosta WJ, 1996, Intercultural Communication Competence: A Synthesis. Communication Yearbook, 19: 353-383.

[8] Chen GM, Starosta WJ, 1997, A Review of the Concept of Intercultural Sensitivity. Human Communication, 1: 1-16.

[9] Xiao SQ, 2014, Empirical Study Intercultural Sensitivity of English Majors in Normal Universities. Journal of Liaoning University of Engineering and Technology (Social Science Edition), 16(1): 87-91.

[10] Han XH, 2014, Current Situation and Reflection on the Cultivation of College Students' Intercultural Communication Competence - Taking College English Teachers as the Investigation Dimension. Journal of Foreign Languages, 2014(3): 106-110.

[11] Altan MZ, 2018, Intercultural Sensitivity A Study of Pre-service English Language Teachers. Journal of Intercultural Communication, 2018(46): 1-17.

[12] Shao SY, Chen JL, 2011, A Survey on Intercultural Communication Sensitivity of Senior High School English Teachers. Journal of Foreign Languages, 2011(3): 144-147.

[13] Wang WT, Zhou MM, 2016, Validation of the Short Form of the intercultural Sensitivity Scale (ISS15). International Journal of Intercultural Relations, 55: 1-7.

[14] Paige RM, Jorstad HL, Siaya L, et al., 2003, Culture Learning in Language Education: A Review of the Literature, in Lange DL, Paige RM, (Eds.), Culture as the Core: Perspectives on Culture in Second Language Learning, Information Age Publishing, USA, 173-236. 